\title{
Autumn dispersal and limited success of reproduction of the deepbody bitterling (Acheilognathus longipinnis) in terrestrialized floodplain
}

\author{
Shigeya Nagayama ${ }^{1,2, *}$, Munehiro Oota ${ }^{2}$, Tomohiko Fujita ${ }^{2}$, Jyun-ichi Kitamura ${ }^{3}$, \\ Toshifumi Minamoto $^{4}{ }^{\circ}$, Seiichi Mori ${ }^{5}$, Masayuki Kato ${ }^{2}$, Naofumi Takeyama ${ }^{2}$, Fumiya Takino ${ }^{6}$, \\ Ryuji Yonekura $^{7}$ and Hiroki Yamanaka ${ }^{6}$ \\ ${ }^{1}$ Regional Adaptation Research Center, Gifu University, 1-1, Yanagido, Gifu, Gifu 501-1193, Japan \\ ${ }^{2}$ Civil Engineering and Eco-technology Consultants Co., Ltd., 2-23-2, Higashi-ikebukuro, Toshima, Tokyo 170-0013, Japan \\ ${ }^{3}$ Mie Prefectural Museum, 3060 Isshinden-koudubeta, Tsu, Mie 514-0061, Japan \\ ${ }^{4}$ Graduate School of Human Development and Environment, Kobe University, 3-11, Tsurukabuto, Nada-ku, Kobe, Hyogo 657-8501, \\ Japan \\ ${ }^{5}$ Gifu-kyoritsu University, 5-50, Kitakata, Ogaki, Gifu 503-8550, Japan \\ ${ }^{6}$ Faculty of Advanced Science and Technology, Ryukoku University, 1-5 Yokotani, Seta-Oe Cho, Otsu, Shiga 520-2194, Japan \\ ${ }^{7}$ Gifu Prefectural Research Institute for Fisheries and Aquatic Environments, Kawashimakasada, Kakamigahara, Gifu 501-6021, Japan
}

Received: 28 June 2021 / Accepted: 14 January 2022

\begin{abstract}
The terrestrialization of floodplains has become a concern to river managers and ecologists because it has degraded habitats for floodplain-dependent organisms. We examined the temporal distributions of the endangered deepbody bitterling (Acheilognathus longipinnis) throughout its life history, which is an autumn-spawning annual fish spending its egg and larval stages in unionid mussels and emerging in spring, to understand its population decline in the terrestrialized floodplains of the Kiso River, central Japan. We first validated our $A$. longipinnis environmental DNA (eDNA) sampling method and observed an $89.3 \%$ probability of consistency between the eDNA and the direct capture surveys of 56 floodplain waterbodies (FWBs). Subsequently, the temporal distributions with autumn dispersal ( 9 of $14 \mathrm{FWBs})$ were found using time-series eDNA samples collected from $14 \mathrm{FWBs}$ on a floodplain with a length and width of 1.4 and $0.2 \mathrm{~km}$, respectively. In the following spring, juveniles were only detected in the two FWBs connected to the river channel. Moreover, the direct capture data revealed that juveniles occurred in $52.9 \%(9 / 17)$ of the connected FWBs, but only in $5.1 \%$ $(2 / 39)$ of the FWBs isolated from the river channel. Autumn dispersal of $A$. longipinnis would be disadvantageous for reproduction in terrestrialized floodplains with numerous isolated FWBs.
\end{abstract}

Keywords: Endangered species / environmental DNA / floodplain-dependent fish / larval emergence / temporal distribution

\section{Introduction}

Floodplains are biodiversity hotspots in lowland rivers (Tockner and Stanford, 2002). However, they have been terrestrialized in several regulated rivers: the floodplain surface elevation relative to the main river channel has increased and marshy environments have degraded because of anthropogenic riverbed incision and flow regulation (Marston et al., 1995; Takahashi and Nakamura, 2011). Terrestrialization coincides with decreases in hydrological connectivity or inundation frequency and tree cover expansion in floodplain environments

\footnotetext{
${ }^{*}$ Corresponding author: nagayama@gifu-u.ac.jp
}

(Baptist et al., 2004; Nakamura et al., 2017). Therefore, terrestrialization may be associated with floodplain habitat degradation in Japan (Negishi et al., 2012a, b) and other nations (Bravard et al., 1997; Lewis et al., 2000; Baptist et al., 2004).

Deepbody bitterling (Acheilognathus longipinnis), also known as Itasenpara bitterling, is a temperate freshwater fish belonging to the subfamily Acheilognathinae of the family Cyprinidae and endemic to central Japan. It was formerly distributed throughout the Lake Biwa-Yodo River system and the Nobi and Toyama plains. However, its current distribution in each region is considerably limited because of habitat alteration due to intensive agricultural and urban development of floodplains. Consequently, it has been designated as an endangered species by domestic and international institutes. 
The natural habitat of $A$. longipinnis probably comprised of various waterbodies formed in the broad floodplains of lowland rivers. However, the A. longipinnis habitat has been reduced to inter-levee floodplain waterbodies (FWBs) and small agricultural streams (Ogawa et al., 2000; Kitamura et al., 2009; Nishio et al., 2017a). In our study segment of the Kiso River on the Nobi Plain, A. longipinnis inhabits FWBs formed in the terrestrialized inter-levee floodplains.

A. longipinnis is an autumn-spawning annual fish. Its unique reproductive ecology involves live freshwater mussels (Unionidae) (Nishio et al., 2015). A . longipinnis deposits its eggs in the gills of mussels. There, the eggs hatch in a few days and the larvae overwinter. Then juveniles emerge from the hosted mussels in the following spring and rapidly grow and mature until autumn (Nishio et al., 2015). There have been recent advances in in situ studies on $A$. longipinnis, including those on its reproductive ecology, life history, and habitats (Kitamura et al., 2009; Nishio et al., 2012, 2015, 2017a, b). However, we have little understanding of their population decline over the last half-century, during which time floodplain terrestrialization progressed. Previous studies on the present study segment disclosed that terrestrialization has decreased the inundation (disturbance) frequency of the floodplains, and this resulted in the decline of unionid mussel populations indispensable for A. longipinnis reproduction (Negishi et al., 2008, 2012a, b). These changes in biotic/abiotic environmental conditions would negatively affect the $A$. longipinnis populations.

Environmental DNA (eDNA) sampling is a powerful tool for aquatic organism detection (Rees et al., 2014). It has typically been used to determine the distributions of rare or endangered species as it is sensitive and non-invasive (Jerde et al., 2011; Sigsgaard et al., 2015). It is also cost-effective for field surveys (Darling and Mahon, 2011) and supports wide and repeated distribution assessments. Hence, eDNA was deployed here to monitor the distribution of the endangered A. longipinnis throughout its lifetime.

We hypothesized that $A$. longipinnis disperse to FWBs all over the inter-levee floodplain during flooding; however, their dispersal is disadvantaged in terrestrialized floodplains as more FWBs are unsuitable for their inhabitation and/or reproduction. In this study, we examined the temporal distribution and success/ failure of the reproduction of $A$. longipinnis with reference to the FWB environments in the terrestrialized inter-levee floodplain. These are vital pieces of ecological information for population conservation and habitat management in A. longipinnis residing in terrestrialized floodplains. We first established the validity of our A. longipinnis eDNA sampling method adapted to fit our study site. We then examined the temporal distribution of A. longipinnis throughout its free-swimming period using timeseries eDNA samples and their relationships with FWB environments. We also examined the relationship between juvenile emergence and FWB type using distribution data derived from eDNA and direct capture.

\section{Materials and methods}

\subsection{Study site}

The study was conducted in a lowland segment 26.0 $41.0 \mathrm{~km}$ from the mouth of the Kiso River in central Japan (Fig. 1). Here is the present distribution range of $A$. longipinnis in the Kiso River on the Nobi Plain (Fig. 1). The drainage area was $5275 \mathrm{~km}^{2}$. The riverbed slope of the study segment was $\sim 0.02 \%$. Over the last decade (2009-2018), the ordinary and maximum annual water discharges ranged from 136 to $221 \mathrm{~m}^{3} \mathrm{~s}^{-1}$ and 2887 to $11054 \mathrm{~m}^{3} \mathrm{~s}^{-1}$, respectively. Relatively high flows were observed between June and July (East Asian rainy season) and between September and October (typhoon season). From November to May, the flows were relatively low and stable. Levees were constructed along both sides of the study segment. Floodplains and FWBs occurred in the inter-levee zone. There were two types of FWBs according to their connectivity to the main river channel: one was a connected type (connected FWB), which was perennially connected to the river channel, and another was an isolated type (isolated FWB), which was intermittently connected to the river channel when the water level increased.

Until the 1970s, most of the inter-levee floodplain in the Kiso River consisted of sand bars. However, terrestrialization and subsequent tree establishment have rapidly progressed since the 1980 s, resulting in most of the floodplain being covered by trees (Negishi et al., 2008; Nagayama et al., 2015, 2017).

\subsection{Fish and eDNA samplings for validation}

There were 152 FWBs ( 40 connected and 112 isolated) in the study segment. Most of the FWBs were in the five sites along both sides of the riverbanks (Fig. 1). Fifty-six FWBs (17 connected and 39 isolated) with various areas and elevations were arbitrarily selected from the five sites for the validation of the eDNA sampling method. Direct capture of $A$. longipinnis and eDNA sampling (see below) were conducted in all 56 FWBs from May 28, 2018, to June 2, 2018, when juvenile $A$. longipinnis ( $\sim 10 \mathrm{~mm}$ body length) emerged from the hosted mussels.

The eDNA sampling was conducted as follows. First, 1-L water samples were collected from the water surfaces at five different sampling points, which were set at approximately equal intervals along the shoreline according to the perimeter of each FWB. The water samples were pooled in a bucket and a 400-mL subsample was transferred to a polypropylene bottle for the eDNA assay. Benzalkonium chloride solution $(0.1 \% \mathrm{w} / \mathrm{v})$ was added to the bottles to preserve the eDNA (Yamanaka et al., 2017). The samples were stored in a cooler box along with a 400-mL distilled water (DW) blank, taken to a laboratory, and refrigerated. The bucket used to pool the water was decontaminated with bleach after sampling. The standard water volume for an eDNA assay is in the range of 1-2 L (Rees et al., 2014). The 400-mL sample volume used here facilitated field portability and turbid water sample filtration.

Direct fish capture was conducted for each of the 56 FWBs. Juvenile A. longipinnis emerged from mussels and aggregated on the water surface near the FWB shore (Ogawa et al., 2000). An operator with a hand net and a small transparent tank waded slowly along the shore, enclosed a fish cluster by lifting the hand-net frame off the water surface, and scooped the fish and water with a transparent tank used for A. longipinnis identification and enumeration. Fish were released back into the FWB water immediately after the record was obtained. The preceding steps were repeated for each FWB until all shore areas $(\sim 3 \mathrm{~m}$ from the bank) were searched. The direct capture survey was conducted with the permission of the Ministry of 
the Environment, the Agency for Cultural Affairs, and Aichi and Gifu prefectures.

\subsection{DNA filtration, extraction, and real-time PCR}

The water samples were pulled by vacuum through a $0.7-\mu \mathrm{m}$ membrane filter $(47-\mathrm{mm}$ GF/F glass fiber; GE Healthcare, Little Chalfont, UK) within 3 days of sampling. The cooler blank was simultaneously filtered. A filtered 'equipment blank' (200 mL DNA-free DW) was incorporated before and after each sample filtration day. The 'cooler blank' and 'equipment blank' were negative controls and their DNA levels were measured to identify any DNA contamination from field preparation and transportation, filter equipment, or background sources. The filters were wrapped in DNA-free aluminum foil and stored at $-20{ }^{\circ} \mathrm{C}$ until eDNA extraction.

DNA extraction was performed as previously described (Yamanaka et al., 2016). The final volume of each extracted DNA sample was $100 \mu \mathrm{L}$ and all samples were stored at $-20^{\circ} \mathrm{C}$ until the PCR assay.

The eDNA was analyzed with Real-Time TaqMan PCR in the PikoReal Real-Time PCR system (Thermo Fisher Scientific, Waltham, MA, USA). Mitochondrial cytochrome b gene fragments $(131 \mathrm{bp})$ were amplified and with a TaqMan probe and the following primers: Alon_CyB-forward: 5'-GTCAGCAGTACCCTACATAGGAGATG-3'; Alon_CyB-reverse: 5'GCGGCGGCAACAACA-3'; and Alon_CyB-probe: 5'-FAMTAACCCGATTTTTTGCCTTCCACTTCCTCT-TAMRA-3'. The species-specificity of the primers/probe set was confirmed via PCR using templates of closely related species (Appendix A).

Each TaqMan reaction mixture contained $900 \mathrm{nM}$ of each primer (Alon_CyB-forward and reverse), $125 \mathrm{nM}$ Alon_CyBprobe, $10 \mu \mathrm{L}$ Master Mix (TaqMan Environmental Master Mix 2.0; Life Technologies, Carlsbad, CA, USA), 0.1 U uracilDNA glycosylase (Thermo Fisher Scientific, Waltham, MA, USA), and $2 \mu \mathrm{L}$ DNA solution. The total reaction mixture volume was equivalent to $20 \mu \mathrm{L}$ of DNA-free water. The PCR conditions were as follows: $50^{\circ} \mathrm{C}$ for $2 \mathrm{~min}$; $95^{\circ} \mathrm{C}$ for $10 \mathrm{~min}$; 55 cycles of $95^{\circ} \mathrm{C}$ for $15 \mathrm{~s}, 60^{\circ} \mathrm{C}$ for $1 \mathrm{~min}$, and $20^{\circ} \mathrm{C}$ for $10 \mathrm{~s}$. There were three replicates per water sample and three positive controls. Three no-template controls were included in each PCR run. A positive result for any replicate indicated the presence of $A$. longipinnis DNA. No amplification was detected for any negative control.

\subsection{Temporal distribution survey by eDNA}

Fourteen FWBs located on the Site 4 floodplain $(1.4 \mathrm{~km}$ long and $0.2 \mathrm{~km}$ wide, Fig. 1) were selected to examine the temporal distribution of $A$. longipinnis in the terrestrialized floodplain throughout its free-swimming period (Tab. 1). These FWBs were included in the 56 above-mentioned FWBs and consisted of both FWB types from a range of areas and elevations. The water from these FWBs was sampled for the eDNA assays on May 28, July 18, August 13, September 25, and October 25, 2018. All samples were subjected to filtration, extraction, and real-time PCR as previously described. Water samples and direct capture data for May 28, 2018, were shared between this distribution assay and the validation of the sampling method. In addition, from May 2019 to early June 2019 (next spring), the emergence of juvenile $A$. longipinnis was assessed by direct capture surveys as previously described to evaluate the success/failure of reproduction in the $14 \mathrm{FWBs}$.

To examine the relationship between flooding and A. longipinnis distribution, the hourly water levels at the nearest gauging station of a national institution (Okoshi: $35^{\circ} 18^{\prime} 42^{\prime \prime}$ N, $136^{\circ} 44^{\prime} 17^{\prime \prime}$ E) were used (Fig. 1).

\subsection{FWB characteristics}

Surface area, perimeter, and type (connected or isolated) were evaluated for the 56 FWBs wherein eDNA and fish were sampled between May 28, 2018, to June 2, 2018. The shortest distances from the shore of the main river channel and connecting height, which is an elevation when FWBs connect to the water surface of the main river channel during flooding, were estimated for 14 of the 56 FWBs to examine their relationships to the temporal distribution (Tab. 1). For these estimations of FWB characteristics, aerial photographs captured in January 2018 and a digital elevation model based on airborne laser scanning data for December 2017 were applied to ArcMap (ArcEditor v. 10.0; Esri Co., Redlands, CA, USA). In the 14 FWBs, unionid mussels were also surveyed in 2018 and 2020 based on the methods of Negishi et al. (2012b) following standardized protocols for mussel sampling (Tab. 1) because mussels are indispensable for A. longipinnis oviposition and may be an important factor of FWB selection for reproduction.

\subsection{Statistical analyses}

The eDNA detection vs. non-detection was modeled as a function of juvenile $A$. longipinnis abundance with a binomial error distribution and logit link function using generalized linear models (GLMs). The data used in this model were obtained from the 56 FWBs in spring 2018. Models were built for the individual number per unit area and the individual number per unit FWB perimeter. Juvenile A. longipinnis are distributed near the FWB shore immediately after their emergence from mussels (Ogawa et al., 2000). Hence, abundance per unit perimeter was considered. Model significance was evaluated via a likelihood ratio test against a null model.

A Kruskal-Wallis test was performed to compare environmental variables (area, distance, and connecting height) among the isolated FWBs wherein eDNA was detected $(\mathrm{N}=7$ on September 25 and $\mathrm{N}=8$ on October 25) or not detected $(\mathrm{N}=5$ on September 25 and $\mathrm{N}=4$ on October 25). This test assessed whether site selection of A. longipinnis during the spawning season was influenced by the FWB environments. The connected FWBs were not evaluated in this test as the sample size was only two.

A Fisher's exact test was performed to compare the difference in the presence/absence of juvenile A. longipinnis between connected $(\mathrm{N}=17)$ and isolated $(\mathrm{N}=39)$ FWBs during the emergence period of spring 2018.

All statistical analyses were performed in $\mathrm{R} \mathrm{v}$. 3.6.3 (R Core Team, 2020) at a 0.05 significance level. 


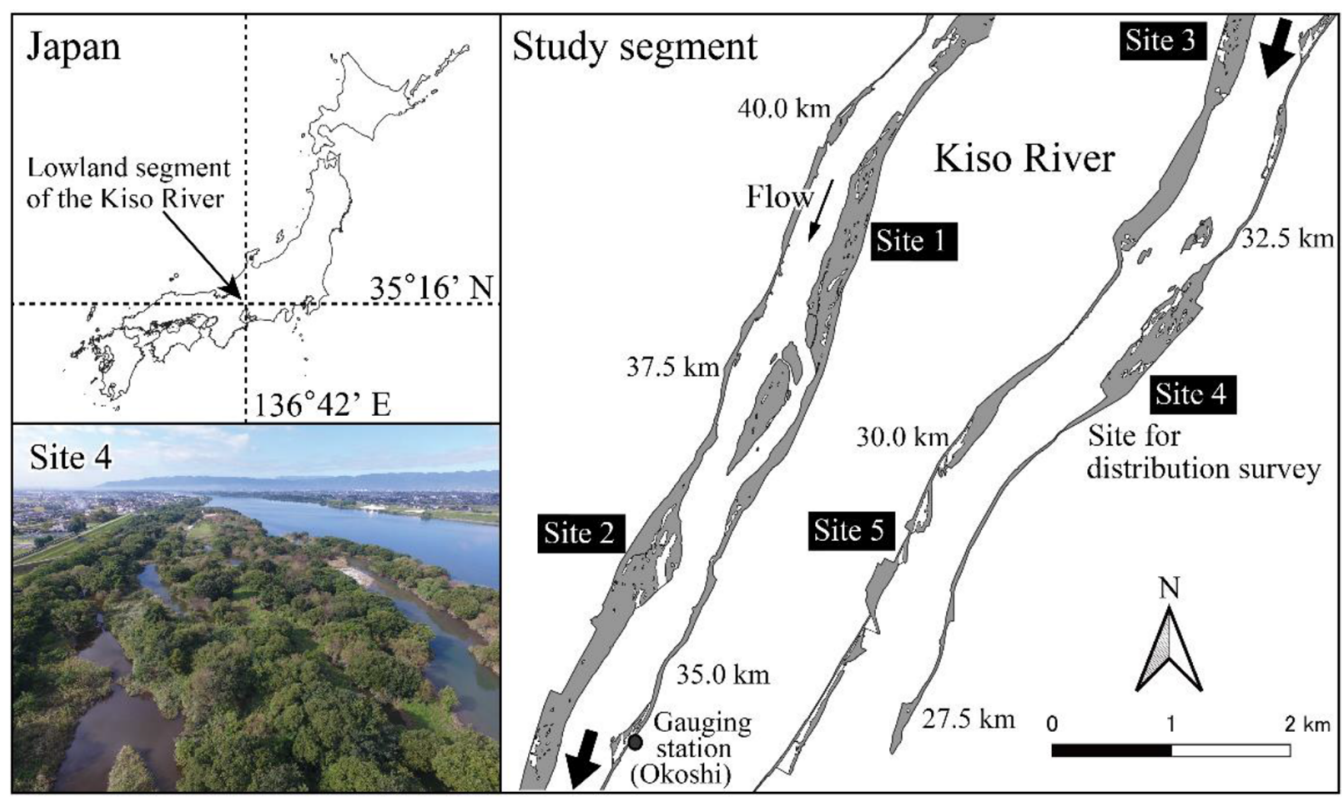

Fig. 1. Study segment and site locations. Distance $(\mathrm{km})$ from river mouth is shown along river channel. Sites $1-5$ in black boxes denote five main floodplains including most floodplain waterbodies. Site 4 was a study site for temporal distribution of $A$. longipinnis. Thin and thick arrows denote flow direction and a join in the map, respectively.

\section{Results}

\subsection{Sampling method validation}

A. longipinnis juveniles were captured in 11 of the 56 FWBs in spring 2018 (Fig. 2). The eDNA was detected in six of 11 FWBs where juveniles were captured and in one of 45 FWBs wherein no juvenile was captured (Fig. 2). The probability of consistency between the eDNA (detection/nondetection) and direct capture (presence/absence) data was $89.3 \%(50 / 56)$. The GLMs showed significant relationships between eDNA detection and juvenile abundance (Fig. 3). Logistic regression curves based on the models predicted that eDNA could be detected when juvenile A. longipinnis abundance was $>1$ per $100 \mathrm{~m}^{2}$ (Fig. 3a) or $>1$ per $10 \mathrm{~m}$ perimeter (Fig. $3 \mathrm{~b}$ ).

\subsection{Temporal distribution}

No A. longipinnis eDNA was detected, and individuals were not captured from all $14 \mathrm{FWBs}$ located on floodplain Site 4 on May 28, 2018 (Tab. 2). The eDNA was detected in only a few FWBs during the summer growing period (July 18 to August 13). During the autumn spawning period (September 25 to October 25), however, eDNA was detected in nine FWBs on each sampling day (Tab. 2). Of the eDNA-detected FWBs, seven and eight were the isolated type on September 25 and October 25, respectively.

Large floods, which connected all FWBs to the main river channel, occurred from late June to early July before eDNA sampling on July 18 (Fig. 4). They also occurred in early September and early October before eDNA sampling on September 25 and October 25, respectively (Fig. 4).

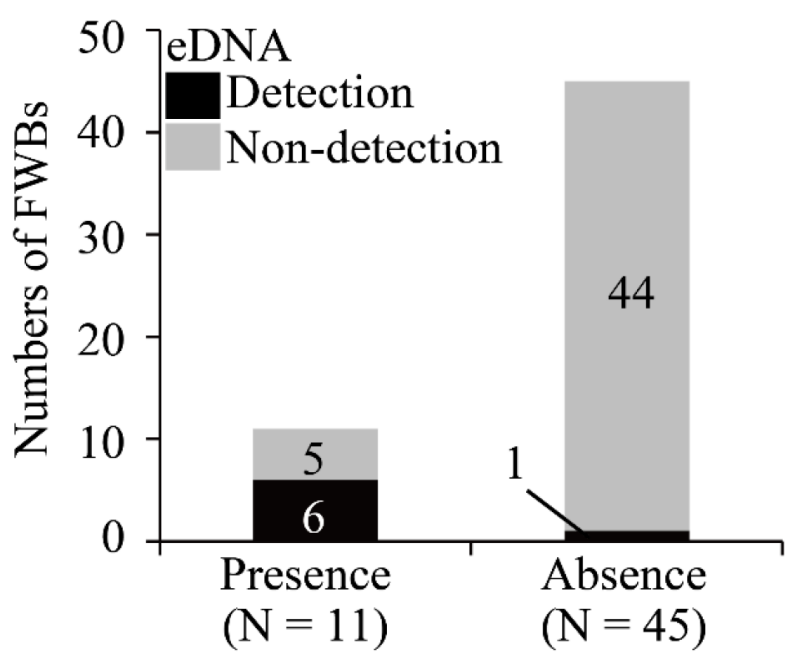

Fig. 2. Number of floodplain waterbodies where A. longipinnis individuals were captured (presence) or not captured (absence) with separation at eDNA detection and non-detection.

The Kruskal-Wallis tests disclosed that during autumn (September 25 and October 25), the area, distance, and connecting height of the isolated FWBs where eDNA was detected did not differ from those of the isolated FWBs where eDNA was not detected $(P>0.05$ in all tests). In addition, the presence/absence of mussels were not consistent with the detection/non-detection of $A$. longipinnis eDNA, as they were present in zero of seven and one of eight eDNA-detected isolated FWBs on September 25 and October 25, respectively, 
a)

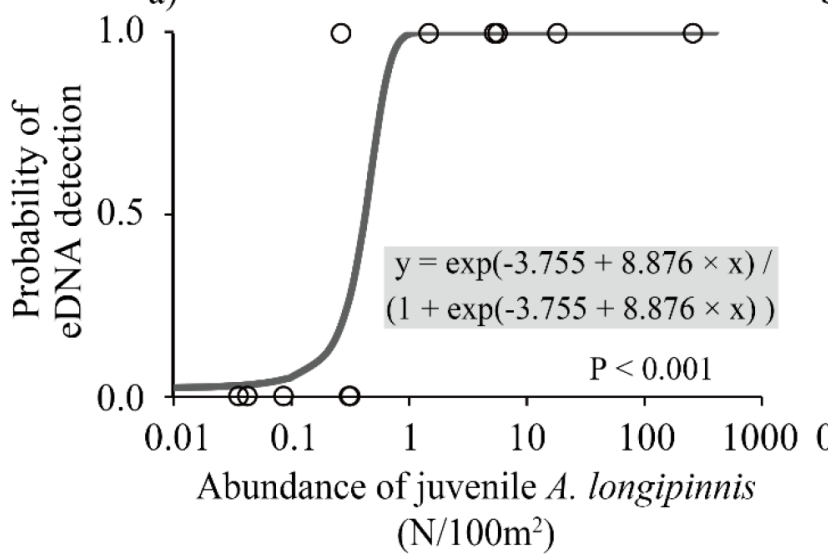

b)

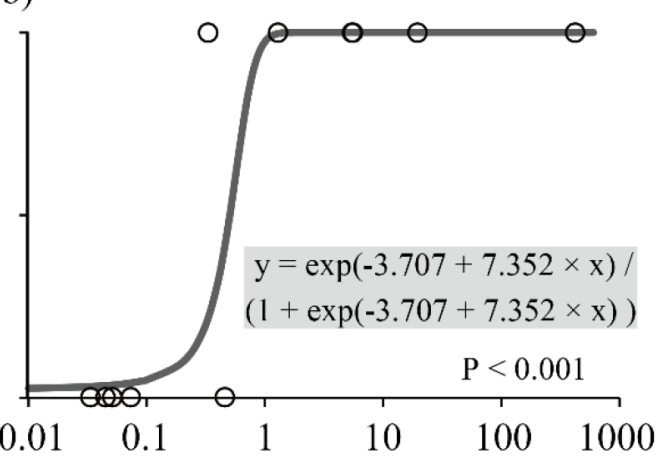

Abundance of juvenile $A$. longipinnis

$(\mathrm{N} / 10 \mathrm{~m})$

Fig. 3. Probability of eDNA detection for the abundance of juvenile $A$. longipinnis per unit area (a) and perimeter (b). Plots with 0 abundance are not represented, because the $\mathrm{x}$-axis is displayed in logarithmic form, although 0 abundance data were used in building the models and drawing these figures. Statistically significant models are indicated by solid lines and formulae. $P$-values based on likelihood ratio test are also shown.

Table 1. General characteristics of 14 floodplain waterbodies (FWBs) during ordinary-flow periods.

\begin{tabular}{llllll}
\hline FWB & Type & Area $\left(\mathrm{m}^{2}\right)$ & Distance $(\mathrm{m}) \dagger$ & Connecting height $(\mathrm{m}) \dagger$ & Unionid mussel $(\mathrm{CPUE}) \S$ \\
\hline 1 & Connected & 12898 & 0 & 0 & 16.9 \\
2 & Connected & 7529 & 0 & 0 & Presence \\
3 & Isolated & 3213 & 31 & 3.90 & 0 \\
4 & Isolated & 2223 & 186 & 4.09 & 25.0 \\
5 & Isolated & 1530 & 216 & 4.09 & 13.8 \\
6 & Isolated & 468 & 97 & 4.40 & 0 \\
7 & Isolated & 3044 & 185 & 4.59 & 0 \\
8 & Isolated & 1837 & 137 & 4.59 & 0 \\
9 & Isolated & 988 & 137 & 4.59 & 0 \\
10 & Isolated & 659 & 244 & 4.59 & 0 \\
11 & Isolated & 266 & 200 & 4.59 & 0 \\
12 & Isolated & 1436 & 168 & 4.80 & 0 \\
13 & Isolated & 744 & 223 & 4.80 & 0 \\
14 & Isolated & 613 & 227 & 4.80 & \\
\hline
\end{tabular}

$\uparrow$ Shortest distance from main river channel.

\$ Elevation (water level) connecting with main river channel based on digital elevation map derived from airborne laser scanning in December 2017.

$\S$ Number of individual mussels caught by survey personnel in $1 \mathrm{~h}$ (CPUE: catch per unit effort) based on intensive survey in 2018-2020 conducted with reference to Negishi et al. (2012b). "Presence" was derived from our sporadic survey that did not apply the protocols of Negishi et al. (2012b).

and absent in two of five and two of four isolated FWBs without eDNA detection on September 25 and October 25, respectively.

\subsection{Emergence}

Between late May and early June 2019 (next spring) during the juvenile $A$. longipinnis emergence period, individuals were captured in only two connected FWBs (Tab. 2). In contrast, no individuals were caught in any of the 12 isolated FWBs regardless of eDNA detection or non-detection during the previous autumn spawning season (September 25 and October 25, 2018) (Tab. 2).

During spring 2018, nine out of 11 FWBs where juvenile A. longipinnis were captured were of the connected type (Fig. 5). A. longipinnis juveniles were found in nine out of 17 (52.9\%) of the connected FWBs but in only two out of 39 (5.1\%) of the isolated FWBs (Fig. 5). The difference in the presence/ absence of juveniles between connected and isolated FWBs was statistically significant (Fisher's exact test $P<0.001$ ). 
S. Nagayama et al.: Knowl. Manag. Aquat. Ecosyst. 2022, 423, 4

Table 2. Detection (+) or non-detection (-) of A. longipinnis via eDNA and direct capture. There were three replicates per water sample, and the number of replicates with eDNA detection is shown in parentheses.

\begin{tabular}{|c|c|c|c|c|c|c|c|}
\hline \multirow{2}{*}{$\mathrm{FWB} \dagger$} & \multicolumn{2}{|c|}{ May 28} & \multirow{2}{*}{$\frac{\text { July } 18}{\text { eDNA }}$} & \multirow{2}{*}{$\begin{array}{l}\text { August } 13 \\
\text { eDNA }\end{array}$} & \multirow{2}{*}{$\begin{array}{l}\text { September } 25 \\
\text { eDNA }\end{array}$} & \multirow{2}{*}{$\frac{\text { October } 25}{\text { eDNA }}$} & \multirow{2}{*}{$\begin{array}{l}\text { Next spring } \\
\text { (May-June) }\end{array}$} \\
\hline & Direct capture & eDNA & & & & & \\
\hline $1, \mathrm{c}$ & - & - & - & - & $+(3)$ & - & + \\
\hline $2, \mathrm{c}$ & - & - & $+(1)$ & - & $+(2)$ & $+(3)$ & + \\
\hline $3, \mathrm{i}$ & - & - & - & - & $+(2)$ & $+(2)$ & - \\
\hline $4, \mathrm{i}$ & - & - & - & $+(1)$ & - & - & - \\
\hline $5, \mathrm{i}$ & - & - & - & - & - & $+(1)$ & - \\
\hline $6, \mathrm{i}$ & - & - & - & - & $+(3)$ & - & - \\
\hline $7, \mathrm{i}$ & - & - & - & $+(1)$ & - & - & - \\
\hline $8, \mathrm{i}$ & - & - & - & - & $+(1)$ & $+(1)$ & - \\
\hline $9, \mathrm{i}$ & - & - & - & - & $+(1)$ & $+(1)$ & - \\
\hline $10, \mathrm{i}$ & - & - & - & - & - & $+(2)$ & - \\
\hline $11, \mathrm{i}$ & - & - & $+(1)$ & - & $+(1)$ & - & - \\
\hline $12, \mathrm{i}$ & - & - & - & - & $+(3)$ & $+(1)$ & - \\
\hline $13, \mathrm{i}$ & - & - & - & - & - & $+(1)$ & - \\
\hline $14, \mathrm{i}$ & - & - & $+(1)$ & - & $+(2)$ & $+(3)$ & - \\
\hline
\end{tabular}

$\dagger$ c: connected FWB; i: isolated FWB.

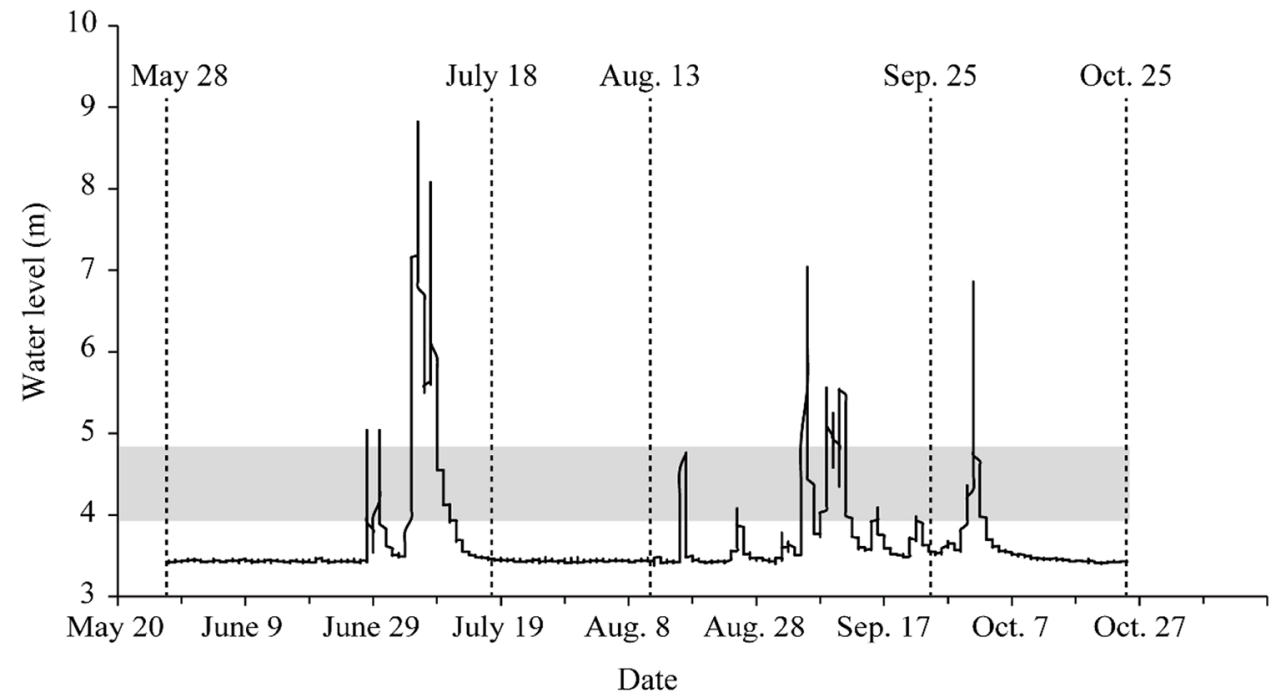

Fig. 4. Hourly water levels at Okoshi gauging station during survey period (May 28 to October 25) in 2018. Sampling dates for eDNA are shown. Gray belt denotes water level (elevation) range that targets FWBs connected with the main river channel. When water level gets beyond the upper belt range, all FWBs and river channel connect.

\section{Discussion}

\section{1 eDNA sampling method validation}

The eDNA sampling methods are adjusted in accordance with the ecological characteristics of the target species and its waterbody environment (Rees et al., 2014; Takahara et al., 2016). Here, five 1-L samples were drawn from the shorelines of each FWB and pooled before taking a $400-\mathrm{mL}$ subsample for eDNA assay. This eDNA sampling method was validated by a high probability of consistency between the eDNA and direct capture and the significant regression models explaining eDNA detection probability by $A$. longipinnis abundance.

The sampling method was not very sensitive as the eDNA could not be detected in five FWBs wherein juvenile A. longipinnis abundance was very low (1-13 individuals, $0.04-0.34 \mathrm{~N} / 100 \mathrm{~m}^{2}, 0.04-0.51 \mathrm{~N} / 10 \mathrm{~m}$ ). The insensitivity might be attributed to the water volume $(400 \mathrm{~mL})$ of a sample being less than the standard water volume (1-2 L) for an eDNA assay (Rees et al., 2014) and the small number (3) of replicates per water sample in PCR. The probability of eDNA detection should decrease with decreasing eDNA concentration in the 


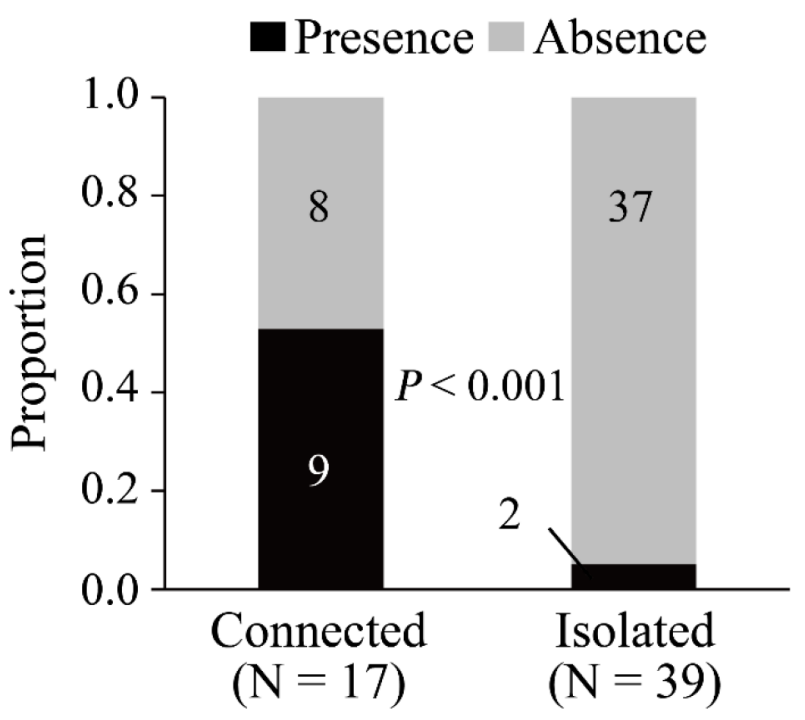

Fig. 5. Proportions of juvenile $A$. longipinnis presence or absence in connected and isolated FWBs. Numerical characters denote numbers of FWBs. $P$-value based on Fisher's exact test is shown in a panel.

environments (Pilliod et al., 2014). The water volume and number of replicates in our method might be insufficient for detecting A. longipinnis in FWBs with low eDNA concentrations. However, eDNA was detected in FWBs with $\geq 42$ individuals $\left(0.28 \mathrm{~N} / 100 \mathrm{~m}^{2}, \quad 0.37 \mathrm{~N} / 10 \mathrm{~m}\right)$, and the regression models predicted that $A$. longipinnis could almost be detected in FWBs with abundance of $>1 \mathrm{~N} / 100 \mathrm{~m}^{2}$ or $>1 \mathrm{~N} / 10 \mathrm{~m}$. Therefore, our sampling method can be used to assess the A. longipinnis distribution in FWBs with a certain degree of accuracy.

4.2 Temporal $A$. longipinnis distribution throughout its free-swimming period

No A. longipinnis individuals or eDNA were found in any of the 14 FWBs on May 28, 2018. However, eDNA was detected in 2-3 FWBs during the summer (July 18 and August 13) and in 9 FWBs during the autumn (September 25 and October 25). Large floods connected the FWBs to the main river channel before the summer and autumn sampling days. Thus, A. longipinnis could have migrated to all FWBs. Nevertheless, the $A$. longipinnis distribution was limited to a few FWBs in the summer, but spread in the autumn. These results indicate that A. longipinnis might move more actively during the spawning season (autumn) than during the growing season (summer). Incidentally, the changes in eDNA detection/non-detection between the summer sampling days, when no flooding occurred, might be due to the extinction of individuals moving into the FWBs or the above-mentioned insensitivity of the sampling method.

During the East Asian rainy season (June to July in central Japan) under the Asian monsoon climate system, numerous floodplain-dependent fish move to spawn preferring freshets or inundations (Saitoh et al., 1988; Iwata, 2006). This might be their evolutionarily acquired habit to find preferable spawning habitats and maintain their distribution area. The typhoon season of September to October (autumn) is another rainy season in central Japan. A. longipinnis might adapt their spawning to the autumn rainy season and, therefore, might actively move into numerous FWBs during typhoon-fed flooding.

In autumn, there was no difference in the environmental characteristics between the isolated FWBs where eDNA was detected and not detected. This suggests that A. longipinnis dispersal during autumn flooding might be not greatly affected by the FWB environments. A. longipinnis appeared to have moved into the FWBs, regardless of whether they were suitable for reproduction or not.

4.3 Relationship between $A$. longipinnis emergence (reproduction) and FWB types

The eDNA analysis results showed that $A$. longipinnis spawners were distributed in the nine FWBs during each autumn sampling day. Nevertheless, juvenile emergence was found in only two connected FWBs by the following spring. These results indicate that their migration to isolated FWBs during the spawning season might not contribute to their reproduction. At our study site, potential habitats that have high inundation frequency and are suitable for unionid mussels have decreased since the 1960s because of floodplain terrestrialization with increases in floodplain height relative to the main river channel (Negishi et al., 2008; Negishi et al., $2012 a, b)$. Alternatively, there was a large increase in the number of small isolated FWBs (Nagayama et al., 2015, 2017) with low inundation frequency that are not conducive to unionid mussel proliferation (Negishi et al., 2012a, b). This might cause the low occurrence $(5.1 \%)$ of $A$. longipinnis emergence in isolated FWBs. This suggests that the inherent autumn dispersal of $A$. longipinnis might now be disadvantageous for its reproduction in terrestrialized floodplain with numerous isolated FWBs, although dispersal would be essential for population persistence.

Unlike isolated FWBs, connected FWBs relatively functioned as $A$. longipinnis reproductive sites. Connected FWBs are also conducive to unionid mussel proliferation: low benthic organic matter levels and infrequent hypoxia contributed to mussel survival and growth (Negishi et al., 2012a, b, 2014; Nagayama et al., 2016). Hypoxia is also a critical limiting factor for bitterling embryo survival in mussel gills (Smith et al., 2000; Kitamura, 2005). In our preliminary investigation on May 11-12, 2017, low dissolved oxygen levels $(0.33-2.77 \mathrm{mg} / \mathrm{L})$ were recorded in an isolated FWB without mussels, and relatively high dissolved oxygen levels $(3.35-10.68 \mathrm{mg} / \mathrm{L})$ were recorded in a connected FWB with mussels and A. longipinnis emergence, although the dissolved oxygen levels were high $(>7 \mathrm{mg} / \mathrm{L})$ in both FWBs on February 6-7, 2018. Connected FWBs can provide suitable habitats for mussels and foster bitterling embryo development and emergence from mussels.

No A. longipinnis emergence was observed in certain isolated FWBs containing both $A$. longipinnis spawners and mussels, indicating that $A$. longipinnis reproduction might not necessarily succeed even in the presence of mussels. The reproduction failure may be related to hypoxia inhibiting bitterling embryo development (Smith et al., 2000; Kitamura, 2005) because hypoxia occurs more frequently in isolated than connected FWBs (Negishi et al., 2012a). 


\section{Conclusions}

A. longipinnis may find preferable spawning habitats and maintain their distribution in pristine broad floodplains via dispersal to various types of waterbodies, such as ponds and creeks. In the inter-levee terrestrialized floodplain of our study site, however, many of the isolated FWBs did not function as A. longipinnis reproduction sites and might have caused abortive autumn dispersal for their reproduction. Its autumn dispersal might be detrimental under the current conditions of the study river site. This finding raises important concerns on the persistence of the A. longipinnis population there. Current hydrogeomorphic conditions facilitate inter-levee floodplain terrestrialization. Therefore, future research should explore ways of increasing functioning reproduction sites, thereby enhancing the reproductive efficiency of $A$. longipinnis.

Migration and dispersal during spawning are life-history strategies in various floodplain-dependent fish (Saitoh et al., 1988; Tonkin et al., 2008). Regardless of how river environments change, their habits would be necessary for searching preferable spawning sites and maintaining their distribution. However, they may be disadvantageous in terrestrialized floodplains because of increases in isolated waterbodies with reduced hydrological connectivity (Marston et al., 1995; Tockner and Bretschko, 1996; Negishi et al., 2012a, b). Low hydrological connectivity or infrequent inundation alter physicochemical environments of floodplain waterbodies and thereby affect the habitat quality (Van den Brink et al., 1993; Lewis et al., 2000; Negishi et al., 2014). Evolutionarily acquired habits of aquatic organisms cannot adapt to the rapidly altered riverine conditions. Attention needs to be paid to detriments of their habits in terrestrialized floodplains. Moreover, restoration efforts that increase the number of connected FWBs and the hydrological connectivity of isolated FWBs are necessary to conserve floodplain-dependent fish in terrestrialized floodplains.

\section{Conflict of interest}

Toshifumi Minamoto and Hiroki Yamanaka are inventors holding a patent for the use of benzalkonium chloride in eDNA preservation.

Acknowledgements. This study was supported by a Kiso River research fund provided by the Ministry of Land, Infrastructure, Transport and Tourism of Japan (MLIT). The authors thank the MLIT and the Ministry of the Environment of Japan (ME) for sharing biophysical data and supporting the field survey.

\section{Appendix A: Checking the specificity of the real-time PCR assay}

\section{Materials and methods}

We newly developed a primer/probe set for specifically amplifying Acheilognathus longipinnis. The mitochondrial DNA cytochrome b sequences of $A$. longipinnis. and potential sympatric Acheilognathus species (A. cyanostigma, A. rhombeus, and A. tabira tabira) were obtained from the National Center for Biotechnology Information (NCBI) database. Using these sequences, we designed species-specific primer/probe sets using Primer Express 3.0 (Thermo Fisher Scientific, Waltham, MA, USA). The specificity of the primer/probe set was then checked by real-time PCR using DNA of bitterling species that may inhabit the study area. In addition to the above-mentioned Acheilognathus species, the total DNA of Tanakia lanceolata, Tanakia limbata, and Rhodeus ocellatus ocellatus were used. Real-time PCR was performed using $100 \mathrm{pg}$ of extracted DNA from the target and related species as templates under the same conditions as those described in the main text. All PCRs were performed with three replicates.

\section{Results}

Alon_CyB-forward: 5'- GTCAGCAGTACCCTACATAGGAGATG-3', Alon CyB-reverse: 5'-GCGGCGGCAACAACA-3', and Alon_CyB-probe: 5'-FAMTAACCCGATTTTTTGCCTTCCACTTCCTCT-TAMRA-3' were designed as the species-specific primers and probe. All three PCR replicates using the extracted DNA of $A$. longipinnis showed successful amplification by the established assay. The averaged Ct value was 27.42. The PCRs for the other species, excluding A. rhombeus, showed no amplification. One of three replicates for A. rhombeus showed amplification; however, the $\mathrm{Ct}$ value was very high (51.99) and considered negligible. Therefore, the designed assay was confirmed to be specific to A. longipinnis.

\section{References}

Baptist MJ, Penning WE, Duel H, et al. 2004. Assessment of the effects of cyclic floodplain rejuvenation on flood levels and biodiversity along the Rhine River. River Res Appl 20: 285-297.

Bravard J-P, Amoros C, Pautou G, et al. 1997. River incision in southeast France: morphological phenomena and ecological effects. Regul Rivers: Res Manag 13: 75-90.

Darling JA, Mahon AR. 2011. From molecules to management: Adopting DNA-based methods for monitoring biological invasions in aquatic environments. Environ Res 111: 978-988.

Iwata A. 2006. Significance of paddy field agriculture for the existence of the kissing loach (Leptobotia curta). Jpn J Conserv Ecol 11: 133-141. (In Japanese with English summary)

Jerde CL, Mahon AR, Chadderton WL, Lodge DM. 2011. "Sightunseen" detection of rare aquatic species using environmental DNA. Conserv Lett 4: 150-157.

Kitamura J. 2005. Factors affecting seasonal mortality of rosy bitterling (Rhodeus ocellatus kurumeus) embryos on the gills of their host mussel. Popul Ecol 47: 41-51.

Kitamura J, Negishi JN, Nishio M, Sagawa S, Akino J, Aoki S. 2009. Host mussel utilization of the Itasenpara bitterling (Acheilognathus longipinnis) in the Moo River in Himi, Japan. Ichthyol Res 56: 296-300.

Lewis WM Jr, Hamilton SK, Lasi MA, Rodríguez M, Saunders JF III. 2000. Ecological determinism on the Orinoco floodplain. BioScience 50: 681-692.

Marston RA, Girel J, Pautou G, Piegay H, Bravard J, Arneson C. 1995. Channel metamorphosis, floodplain disturbance, and vegetation development: Ain River, France. Geomorphology 13: $121-131$.

Nagayama S, Harada M, Kayaba Y. 2015. Can floodplains be recovered by flood-channel excavation? - An example from 
Japanese lowland rivers - . Ecol Civil Eng 17: 67-77. (In Japanese with English summary)

Nagayama S, Harada M, Kayaba Y. 2016. Distribution and microhabitats of freshwater mussels in waterbodies in the terrestrialized floodplains of a lowland river. Limnology 17: 263-272.

Nagayama S, Tashiro T, Kitamura J. 2017. Inland water landscape: structural and functional changes in the ecosystem. In Shimizu H, Takatori C, Kawaguchi N, eds. Labor Forces and Landscape Management - Japanese Case Studies, Springer, Singapore, 107-120.

Nakamura F, Seo JI, Akasaka T, Swanson FJ. 2017. Large wood, sediment, and flow regimes: Their interactions and temporal changes caused by human impacts in Japan. Geomorphology 279: 176-187.

Negishi JN, Kayaba Y, Sagawa S. 2008. Ecological consequences of changing riverscape: terrestrialization of floodplain and freshwater mussels. Civil Eng J 50: 38-41. (In Japanese)

Negishi JN, Katsuki K, Kume M, Nagayama S, Kayaba Y. 2014. Terrestrialization alters organic matter dynamics and habitat quality for freshwater mussels (Unionoida) in floodplain backwaters. Freshw Biol 59: 1026-1038.

Negishi JN, Sagawa S, Kayaba Y, Sanada S, Kume M, Miyashita T. 2012a. Mussel responses to flood pulse frequency: the importance of local habitat. Freshw Biol 57: 1500-1511.

Negishi JN, Sagawa S, Sanada S, et al. 2012b. Using airborne scanning laser altimetry (LiDAR) to estimate surface connectivity of floodplain waterbodies. River Res Appl 28: 258-267.

Nishio M, Soliman T, Yamazaki Y. 2012. Occurrence and spawning locations of the Itasenpara bitterling (Acheilognathus longipinnis) in the Moo River, Toyama, Japan. Jpn J Ichthyol 59: 147-153. (In Japanese with English summary)

Nishio M, Edo K, Yamazaki Y. 2017a. Paddy management for potential conservation of endangered Itasenpara bitterling via zooplankton abundance. Agric Ecosyst Environ 247: 166-171.

Nishio M, Kawamoto T, Kawakami R, Edo K, Yamazaki Y. 2015. Life history and reproductive ecology of the endangered Itasenpara bitterling Acheilognathus longipinnis (Cyprinidae) in the Himi region, central Japan. J Fish Biol 87: 616-633.

Nishio M, Kawamoto T, Kawakami R, Hata Y, Edo K, Yamazaki Y. 2017b. Microhabitat use by the endangered Itasenpara bitterling Acheilognathus longipinnis (Cyprinidae) during the spawning season in the Moo River, Toyama, Japan. Jpn J Ichthyol 64: 25-30. (In Japanese with English summary)

Ogawa R, Nagata Y, Kihira H. 2000. Reviews of researches on habitats of the bitterling, Acheilognathus longipinnis in the Yodo River. Mem Osaka Kyoiku Univ Ser III 49: 33-55. (In Japanese with English summary)
Pilliod DS, Goldberg CS, Arkle RS, Waits LP. 2014. Factors influencing detection of eDNA from a stream-dwelling amphibian. Mol Ecol Resour 14: 109-116.

R Core Team. 2020. R: A language and environment for statistical computing. R Foundation for Statistical Computing, Vienna, Austria. https://www.R-project.org/.

Rees HC, Maddison BC, Middleditch DJ, Patmore JRM, Gough KC. 2014. The detection of aquatic animal species using environmental DNA - a review of eDNA as a survey tool in ecology. $J$ Appl Ecol 51: $1450-1459$.

Saitoh K, Katano O, Koizumi A. 1988. Movement and spawning of several freshwater fishes in temporary waters around paddy fields. $J p n J$ Ecol 38: 35-47. (In Japanese with English summary)

Sigsgaard EE, Carl H, Møller PR, Thomsen PF. 2015. Monitoring the near-extinct European weather loach in Denmark based on environmental DNA from water samples. Biol Conserv 183: 46-52.

Smith C, Reynolds JD, Sutherland WD, Jurajda P. 2000. Adaptive host choice and avoidance of superparasitism in the spawning decisions of bitterling (Rhodeus sericeus). Behav Ecol Sociobiol 48: 29-35.

Takahara T, Yamanaka H, Minamoto T, Doi H, Uchii K. 2016. Current state of biomonitoring method using environmental DNA analysis. Jpn J Ecol 66: 583-599. (In Japanese)

Takahashi M, Nakamura F. 2011. Impacts of dam-regulated flows on channel morphology and riparian vegetation: a longitudinal analysis of Satsunai River, Japan. Landscape Ecol Eng 7: 65-77.

Tockner K, Bretschko G. 1996. Spatial distribution of particulate organic matter (POM) and benthic invertebrates in a riverfloodplain transect (Danube, Austria): importance of hydrological connectivity. Large Rivers 11: 11-27.

Tockner K, Stanford JA. 2002. Riverine flood plains: present state and future trends. Environ Conserv 29: 308-330.

Tonkin Z, King AJ, Mahoney J. 2008. Effects of flooding on recruitment and dispersal of the Southern Pygmy Perch (Nannoperca australis) at a Murray River floodplain wetland. Ecol Manag Restor 9: 196-201.

Van den Brink FWB, de Leeuw JPHM, Van der Velde G, Verheggen GM. 1993. Impact of hydrology on the chemistry and phytoplankton development in floodplain lakes along the Lower Rhine and Meuse. Biogeochemistry 19: 103-128.

Yamanaka H, Motozawa H, Tsuji S, Miyazawa RC, Takahara T, Minamoto T. 2016. On-site filtration of water samples for environmental DNA analysis to avoid DNA degradation during transportation. Ecol Res 31: 963-967.

Yamanaka H, Minamoto T, Matsuura J, et al. 2017. A simple method for preserving environmental DNA in water samples at ambient temperature by addition of cationic surfactant. Limnology 18: 233241.

Cite this article as: Nagayama S, Oota M, Fujita T, Kitamura J-I, Minamoto T, Mori S, Kato M, Takeyama N, Takino F, Yonekura R, Yamanaka H. 2022. Autumn dispersal and limited success of reproduction of the deepbody bitterling (Acheilognathus longipinnis) in terrestrialized floodplain. Knowl. Manag. Aquat. Ecosyst., 423, 4. 